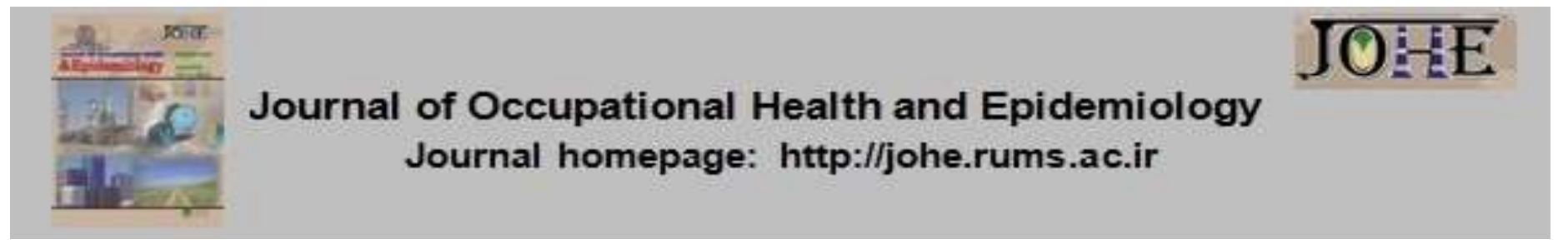

\title{
Intrinsic motivation and psychological factors on wearing helmet among motorcyclists in Gorgan City, Iran, in 2016
}

\author{
Seyed Nabiollah Mirhossini ${ }^{1}$, Seyed Rasoul Davoodi ${ }^{2 *}$, Majid Azimmohseni ${ }^{3}$ \\ 1- MSc in Transportation Planning and Engineering, Department of Civil Engineering, Faculty of Engineering, Golestan University, \\ Gorgan, Iran. \\ 2- Assistant Prof., Department of Civil Engineering, Faculty of Engineering, Golestan University, Gorgan, Iran. \\ 3- Assistant Prof., Department of Statistics, Faculty of Sciences, Golestan University, Gorgan, Iran.
}

Citation: Seyed Nabiollah Mirhossini, Seyed Rasoul Davoodi, Majid Azimmohseni. Intrinsic
motivation and psychological factors on wearing helmet among motorcyclists in Gorgan City,
Iran, in 2016. JOHE. 2018; 7(2):90-6

\section{Article Info}

\section{* Corresponding authors: \\ Seyed Rasoul Davoodi, \\ E-mail: \\ davoodi76ir@gmail.com}

\section{Article history}

Received: Nov, 2017

Accepted: Jan, 2018

10.29252/johe.7.2.90

Print ISSN: 2251-8096 Online ISSN: 2252-0902

Peer review under responsibility of Journal of Occupational Health and Epidemiology

\begin{abstract}
Background: Motorcycles have a higher rate of fatality than cars within the same distance travelled. Head injuries are the main causes of death in motorcycle crashes. The objective of this study is to investigate intrinsic motivation and psychological factors on use of a helmet among motorcyclists in Gorgan City, Iran, in 2016.

Materials and Methods: This cross-sectional survey was conducted among motorcycle riders at randomly selected areas such as fuel stations and service complexes in Gorgan City, Iran, in 2016. The questionnaire was composed of two parts, and 393 people were fully responsive to all questions. The first part included social demographic questions such as age, gender, education, income and marital status. The second part was consisted of questions measuring the intrinsic motivation of incentives and barriers, perceived benefits and barriers, perceived behavioral control, and behavior.

Results: Based on both Pearson correlation and Canonical Correlation Analysis (CCA), the correlation of intrinsic motivation incentives with perceived benefits under the influence of respect for the law was statistically significant $\left(X^{2}=68.751, P<0.010\right),(r=$ $0.491, P<0.010$ ) which would greatly increase helmet use. Intrinsic motivation barriers with perceived benefits was more influenced by the importance of appearance for drivers with a significant correlation $\left(X^{2}=40.655, P<0.010\right),(r=0.281, P<0.010)$, this factor was found to reduce the use of helmets among motorcyclists.

Conclusions: In this study, care for appearance is regarded as an intrinsic motivation which has a significant correlation in almost all psychological factors and finally leads to the use or not use of a helmet. Another key factor which persuades the riders to wear a helmet is respect to the traffic regulations; thus, enforcing the law may be a fundamental strategy for increasing helmet use.
\end{abstract}

Keywords: Public Health, Motorcycle, Psychological Factors, Helmets, Iran.

\section{Introduction}

In the developing countries with low and middle income levels, it is predicted that by 2020 , the number of deaths and disabilities caused by traffic injuries will rise to over 60 percent; therefore, it has allocated the third highest global disease burden to itself (1). According to the Iranian legal medicine organization, the casualties caused by road accidents in Iran is reported as 16,584 people in 2015 (2). A motorcycle is a vehicle which provides the least protection for its riders (3). For every kilometer of the vehicle mobility, the motorcycle rider is 35 times more at the risk of death in comparison to the drivers of other vehicles, and they are 8 times more likely to suffer damage (4). In developing countries with low and medium income levels, a greater rate of motor vehicles is covered by motorcycles. For example, in countries such as India and Malaysia, motorcycles have accounted approximately 69 percent and 60 percent of all vehicles, respectively $(5,6)$. 
According to the World Health Organization (WHO) in 2013, 21 percent of all traffic accidents belonged to the motorcycle accidents (7).

Wearing a helmet can reduce the risk of death and severe damage up to 40 percent and 70 percent, respectively. In the European countries, about 75 percent of head and neck injuries are reported among motorcycle riders; whereas, in the low and middle income and developing countries, this rate is 88 percent $(5,8-10)$. Therefore, the use of helmets can significantly reduce the severity of head injuries in an accident $(11,12)$. Although helmets are regarded as an important savior for motorcyclists at the time of an incident, studies in different countries like China, Malaysia, Vietnam, Thailand, India, Pakistan, Iran, Nigeria, Argentina, Italy and some states of the United States (US) have reported that only a low rate of motorcyclists wear helmets $(6,13,14)$. In Iran, the rates of using helmets for the riders and the passengers are 35 percent and 12 percent, respectively (7). The rules for helping motorcyclists can greatly reduce the risk of death (15-17).

Previous studies investigated the role of psychological factors in the performance of helmet. The present research attempts to study the direct and indirect effects of intrinsic motivation incentives and barriers on wearing a helmet and the psychological factors which are a part of the health belief model and the theory of planned behavior including perceived benefits, perceived barriers, perceived behavioral control, and behavior, which ultimately, lead to a rider's performance for using or not using a helmet (11, $18,19)$.

Thus, by defining the internal motivations of the motorcyclists, the ways in which various aspects of intrinsic motivations affect the psychological factors and the performance of motorcycle riders are analyzed.

Intrinsic motivation is inherent inclination to address the desires and to apply abilities to do the task and to search for optimal challenges in order to master them. This kind of motivation is obtained spontaneously from one's psychological needs, curiosity, and innate efforts to grow. When people are intrinsically motivated, they do a behavior mainly due to the challenge of the activity and its resulting joy. This form of spontaneous behavior occurs not because of the external pressures. In fact, intrinsic motivation provides potential motivation for the individual to pursue his interests and attempts and develop his skills and abilities $(20,21)$.
There are two kinds of intrinsic motivation including incentives and barriers that largely can make a difference in the individuals' behavior. In this research, incentive motivations such as modeling for others, a sense of fear, rights and welfare of others, and respecting their dignity and characters were mentioned. The questions on the intrinsic motivational barriers like apparent beauty, shyness, self-confidence, safety, and tendency to show off were also discussed to analyze the possible reasons for the use or non-use of helmets. Moreover, the effect of intrinsic motivational incentives on wearing a helmet among motorcyclists was studied.

\section{Material and Methods}

This cross-sectional survey was conducted among motorcycle riders at randomly selected areas such as fuel stations and service complexes in Gorgan City, Iran, in 2016. Data collection was conducted in important and crowded places, like gas stations, and entertainment, administrative, and service complexes, in Gorgan City, and Cochran's formula was used for calculating sample size. All the participants gave their permission to be part of this research; moreover, they were informed about anonymous and confidential treatment of data. Totally, regarding the number of observations in such critical areas of the city, 450 motorcycle riders were interviewed, of which 393 participants completed the questionnaires without defect.

The questionnaire was composed of two main parts. The first part included demographic questions such as age, gender, education, income and marital status. The second part was consisted of 28 questions measuring the intrinsic motivation of incentives and barriers, perceived benefits and barriers, perceived behavioral control and behavior. The method of scoring the questions included five options ( $1=$ very low, $5=$ very high). To collect data from the riders, a team of graduate students with full awareness of the importance of transportation was formed. The general trend of filling out the questionnaire lasted about 15 minutes. According to individual demographic data, the average age of the participants was 28.94 years, which was fully cited in descriptive statistics.

A) Perceived benefits vs perceived barriers: As one of the most impressive factors, the perceived benefits are defined as an individual's beliefs about the effects of behaviors suggested for reducing risk or its severity, so that this belief may persuade him to believe in the advantages of doing the performance. Questions like the effect of wearing a 
helmet on reducing injuries are posed. In case of perceived barriers, the individual believes that while performing the target behavior, he will face barriers which lead him to its performance or nonperformance (22). Questions such as the importance of appearance, loss of vision and hearing, weather conditions, convenient communication with the passengers, and restriction in the movements of head and neck are also considered.

B) Perceived behavior control: Another factor affecting the intention of the individuals to perform or not perform the behavior is the perceived behavior control. In the theory of planned behavior, the perceived behavior control is defined as an individual's assessment of the difficulty or ease of a behavior. This control can only determine behavior when the perceived behavior control reflects the real control of the individuals on the desired behavior, given that the perceived behavior control shows the prior experience of the individual and the predicted barriers of performing a behavior $(22,23)$. In this research, questions such as adherence to the traffic regulations and obligations to use a helmet are mentioned.

C) Behavior: Behavior, a combination of knowledge and tendencies with other different factors and ratios, is caused by personal, mental, social, and economic factors as well as current issues that lead to a person's behavior (24). To prove this factor, several questions such as the use of helmets at high speed and different weather conditions including wind and rain or warm and humid air was measured. Finally, the extent to which an individual usually wears a helmet was surveyed

Statistical softwares including SPSS (version 22, IBM Corporation, Armonk, NY, USA) and SAS (version 9.1) were used for data analysis. Cronbach's Alpha for the trustworthiness of the questionnaire was reported to be 0.701 . To analyze various aspects of psychological incentive and disincentives motivations based on the psychological and functional factors, the Pearson's chi-square test was used. Then, to evaluate the overall relationship between intrinsic motivational incentives and barriers for each psychological functional factor, the Canonical Correlation Analysis (CCA) was used. CCA not only evaluates the relationship between intrinsic motivational incentives and barriers but also determines the aspects which have a greater share in this correlation.

\section{Results}

Most men in Iran ride a motorcycle, so it was attempted to do a case study on this social class. According to descriptive statistics, the average age of the participants was 28.94 years which constituted $57.5 \%$ of the participants. Their frequency was between 18-28 years, of whom $59.5 \%(n=234)$ were married and $40.5 \%(n=159)$ were single. In terms of education, $21.4 \%(n=84)$ were under diploma, 42.5\% $(n=167)$ had diploma degree, and $36.1 \%(n=142)$ had academic degrees. Regarding job category, $8.7 \%(n=34)$ were civil servants, $8.4 \%(n=33)$ were employees, $23.4 \%(n=92)$ were service deliverers, $14.0 \%(n=$ $55)$ were shopkeepers, $16.3 \%(n=64)$ were high school and university students, and $29.3 \%$ ( $n=$ 115) had other businesses. Table 1 represents an overview of questions on intrinsic motivation incentives and barriers as well as their mean and standard deviation.

Table 1: Concepts and measures of questions on intrinsic motivation incentives and barriers in the motorcycle riders in Gorgan City, Iran, in 2016

\begin{tabular}{|c|c|c|c|}
\hline VARIABIE & Questions & Mean & SD \\
\hline \multirow{5}{*}{$\begin{array}{c}\text { Intrinsic } \\
\text { motivation } \\
\text { barriers }\end{array}$} & To what extent do you care your apparent beauty? & 3.400 & 1.172 \\
\hline & To what extent are you shy? & 2.660 & 1.198 \\
\hline & To what extent are you self-confident? & 3.330 & 1.101 \\
\hline & To what extent do you feel safety? & 3.070 & 1.146 \\
\hline & To what extent are you willing to show off? & 2.580 & 1.218 \\
\hline \multirow{6}{*}{$\begin{array}{c}\text { Intrinsic } \\
\text { motivation } \\
\text { incentives }\end{array}$} & To what extent do you regard your behavior a suitable pattern for others? & 3.160 & 1.093 \\
\hline & To what extent do you feel afraid? & 2.640 & 1.146 \\
\hline & To what extent do you respect other people's rights and welfare? & 3.920 & 1.124 \\
\hline & To what extent do others respect your character and how important is it to you? & 3.950 & 1.075 \\
\hline & To what extent respecting laws and regulations is important to you? & 3.730 & 1.075 \\
\hline & To what extent are you afraid of death? & 3.180 & 1.419 \\
\hline
\end{tabular}

SD: Standard deviation 
Table 2 shows that respect for the law $\left(X^{2}=\right.$ 68.751, $P<0.010)$ and feeling of fear $\left(X^{2}=50.622\right.$, $P<0.010)$ were both among the intrinsic incentives that led to the institutionalization of law enforcement with the advantage of increasing the use of helmets for the motorcycle riders. The results of the Pearson test also showed that people who considered their behavior as a suitable model for others $\left(x^{2}=39.272, P<0.050\right)$ or expected the others to respect them $\left(x^{2}=47.552\right.$, $\mathrm{P}<0.010$ ) felt more responsible toward the traffic regulations; likewise, motivations such as respect to law $\left(X^{2}=102.159, P<0.010\right)$ and the rights of others $\left(X^{2}=46.122, P<0.010\right)$ made people feel responsible for all traffic rules $\left(X^{2}=46.098, P<\right.$ $0.010)$; and in particular, bounded the motorcycle riders to use a helmet $\left(X^{2}=36.614, P<0.010\right)$.

Table 2: Pearson's chi-square analysis between intrinsic motivation incentives and barriers items in the motorcycle riders in Gorgan City, Iran, in 2016

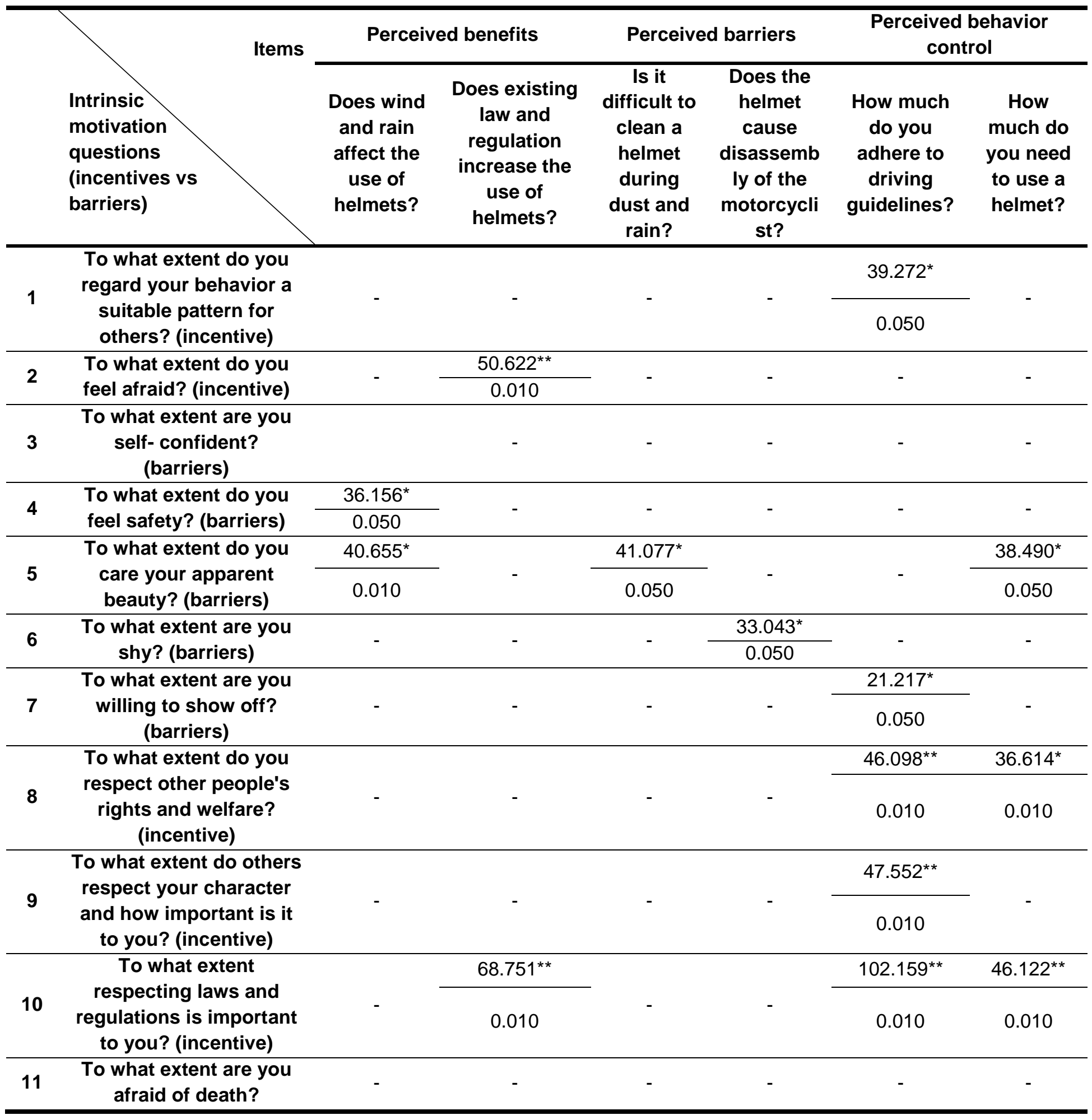

The high number and the number of stars show a meaningful value.

The low number shows the value of $P$

${ }^{*}: \mathrm{P}<0.05,{ }^{* *}: \mathrm{P}<0.01$ 
Furthermore, people who felt safe did not realize the importance of wearing a helmet in severe weather $\left(x^{2}=36.156, P<0.050\right)$. The importance of aesthetics led to the belief that in inclement weather there is no serious need to use a helmet $\left(X^{2}=40.655, P<0.010\right)$.

The importance of aesthetics has also caused the belief that in unpleasant weather, for example rainfall, and also in cases where it is hard to clean the helmet, the rider is more reluctant to wear it $\left(\mathrm{X}^{2}\right.$ $=41.077, \mathrm{P}<0.050)$. Shy riders believed that wearing a helmet makes them look messy and more ashamed $\left(X^{2}=33.043, P<0.050\right)$. Moreover, it was shown that people who care about aesthetics believe that the helmet should not be used $\left(X^{2}=38.490, P<0.050\right)$, and those willing to show up do not believe in driving laws $\left(X^{2}=21.217\right.$, $\mathrm{P}<0.050$ ).

Based on CCA, it was determined that there is a significant relationship between intrinsic motivation barriers and the perceived benefits. This correlation $(r=0.281, P<0.010)$ was mostly affected by the fact that those who care more about their appearance are more willing to use a helmet in poor weather. Based on this analysis, it was also found that the intrinsic motivation incentives and the perceived benefits were significantly related. This relationship can be interpreted by two aspects: The first-class correlation $(r=0.491, P<0.010)$ indicated that the more willing to wear a helmet, the more respectful to the law. The second correlation $(r=0.246, P<$ 0.010 ) showed that fear of the risks can result in increased belief in helmet safety. According to the observed results of the CCA, there was a significant relationship between the intrinsic motivation barriers and the perceived barriers. Given the amount of the correlation $(r=-0.228, P<$ 0.010 ), it was found that feeling of excessive safety leads the riders to complain about wearing a helmet. In addition, there was a significant relationship between the intrinsic motivation incentives and the perceived barriers. The correlation $(r=-0.233, P<0.010)$ expressed that those whose care for their social status nag less about wearing a helmet.

The results of the CCA showed that intrinsic motivation barriers and the perceived behavioral control were significantly correlated. The correlation $(r=-0.211, P<0.050)$ indicated that those who have a higher tendency to show off have less adherence to traffic regulations. Moreover, there was a significant relationship between the riders' intrinsic motivation incentives and their perceived behavioral control. The correlation $(r=0.341, P<0.010)$ showed that those who have greater respect for the law are more committed to the law, especially the traffic rules.

CCA test showed that intrinsic motivation incentives and barriers play no direct role in one's performance, yet the riders' performance under special conditions was directly related to the intrinsic motivations. The CCA $(r=-0.298, P<$ 0.010 ) showed that those who tend to manifest themselves are less likely to use the helmet in rainy and windy weather and at high speeds. In addition, the canonical correlation coefficient $(r=$ $0.329, P<0.010$ ) indicated that those who respect their social prestige not only wear their helmets at high speeds but also they prefer to use them in unpleasant weather. Surprisingly, those who had less fear were unwilling to wear the helmet in distances less than $5 \mathrm{~km}$.

\section{Discussion}

Based on Pearson chi-square test and CCA, it was found that intrinsic motivation incentives with higher perceived benefits were affected by respect to the law and its enforcement advantage, and led to more use of the helmet. In addition, the intrinsic motivation incentives with the perceived behavior control were mostly affected by the respect to the law and commitment to wear a helmet. In similar studies, it was shown that applying mandatory helmet laws can greatly increase the rate of helmet use $(24,25)$. Further, intrinsic motivation barriers with perceived benefits showed that those who care more about their appearance wear their helmet in all weather conditions, so that harsh weather can be regarded as a key factor in using a helmet.

Intrinsic motivation barriers with the perceived barriers and the perceived behavioral control were of importance, since people caring about the way they look, in the atmospheric conditions were forced to use a helmet. However, if the design of the helmet makes it difficult to clean it, the motorcyclists prefer not to use it in order to retain their appearance while riding. The canonical correlation also showed that in the intrinsic motivation barriers with the perceived barriers, the people who care more about their aesthetics use their helmet frequently in different weather conditions. Result of the present study is consistent with that of a study conducted by Wang et al. They showed that good-looking is regarded as an important factor in unwillingness to use helmet (26). 
In addition, intrinsic motivation incentives and the perceived benefits were important since the riders' willingness to wear the helmet originated from their respect to the regulations about using a helmet while riding. In fact, intrinsic motivation barriers with the perceived barriers showed that those who feel safer tend to use their helmet less than others. In another study in which social features were important to the rider, he was encouraged to use the helmet $(27,28)$. These findings were consistent with the results of the present study.

Analyzing the intrinsic motivation incentives and the perceived barriers indicated that those individuals who care about social status are less likely to seek pretext for not using a helmet. The intrinsic motivation barriers with the perceived behavioral control indicated that people who are more likely to show off had less adherence to the traffic rules; whereas, in contrast, regarding the intrinsic motivation incentives, the riders were more encouraged to exhibit greater respect for the law, especially the traffic rules. Finally, it was found that intrinsic motivation incentives and barriers as well as other variables affect a person's behavior indirectly, except in emergency conditions. In most previous studies, the necessity of wearing a helmet was emphasized in terms of the theory of planned behavior. Moreover, in these studies, an individual's performance was formed by variables such as his behavioral intention and perceived susceptibility $(11,19)$.

A number of limitations have to be taken into account when assessing the results of this research. It has only focused on the use of helmets for motorcyclists and not for pillion passengers. Moreover, it was carried out in the winter, and season certainly will affect the results because warm or cold weather affects the use of helmets; therefore, it should be investigated in future. In addition, this study was conducted through selfreporter. In future research, roadside observation can be done with a questionnaire that is more desirable.

\section{Conclusion}

The results of this study showed that the intrinsic motivation incentives and barriers, under special conditions, directly affect an individual's performance. People who care a lot about their social prestige express their willingness to wear a helmet at almost all weather and environmental conditions. In this study, care for appearance was regarded as an intrinsic motivation which had a significant correlation with almost all psychological factors and finally led to the use or not use of a helmet. A helmet with a proper design for windy and rainy weather can increase the riders' desire to wear it. Otherwise, it will be used less often. Another key factor which persuades the riders to wear a helmet is respect and adherence to the traffic regulations; thus, it can be concluded that taking serious steps in enforcing the law may be a fundamental strategy for increasing helmet use. There are several solutions suggested for the relevant readers and organizations such as tests of mental status at the time of taking certification or buying a motorcycle, designing and manufacturing high-quality and efficient helmets which result in the riders' willingness to use it in all weather conditions.

\section{Acknowledgement}

The authors would like to thank all respondents who gave up their time to participate in this research. They would also like to thank the reviewers of this paper for valuable comments.

Conflicts of Interest: None declared.

\section{References}

1. Kopits E, Cropper M. Traffic fatalities and economic growth. Accid Anal Prev 2005; (37)1:169-78.

2. Iranian Legal Medicine Organization. Statistical information, Accidents, statistics of Deaths and injuries for by driving accidents in year 2015. Tehran, Iran: Iranian Legal Medicine Organization; 2016. Available from: http://www.Imo.ir/uploads/tas_12_95.pdf.\#a

3. Musso A, Vuchic VR, Bruun ECh, Corazza MV. A research agenda for public policy towards motorized two-wheelers in urban transport. Paper presented at: The Transportation Research Board 89th Annual Meeting; 2010 Jun 10-14; Washington DC, United States.

4. NHTSA's, National Center for Statistics and Analysis. Traffic safety facts. Washington, DC, United States: National Center for Statistics and Analysis; 2007. 12p.

5. Shuaeib FM, Hamouda AMS, Radin Umar RS, Hamdan MM, Hashmi MSJ. Motorcycle helmet: Part I. Biomechanics and computational issues. J Mater Process Technol 2002; 123(3):406-21

6. World Health Organization. Global status report on road safety 2015. Country profiles (combined), Iran (Islamic Republic of). Geneve: World Health Organization; 2015. Available from:

http://www.who.int/violence_injury_prevention/road_sa fety_status/2015/country_profiles/Iran_Islamic_Republ ic_of.pdf?ua $=1 \& u a=1$

7. Fong MC, Measelle JR, Dwyer JL, Taylor YK, Mobasser A, Strong TM, et al. Rates of motorcycle helmet use and reasons for non-use among adults and children in Luang Prabang, Lao People's Democratic Republic. BMC Public Health 2015; 15:970. 
8. Ledesma RD, López SS, Tosi J, Poó FM. Motorcycle helmet use in Mar del Plata, Argentina: prevalence and associated factors. Int Inj Contr Saf Promot 2015; 22(2):172-6.

9. Chinn B, Canaple B, Derler S, Doyle D, Otte D, Schuller E, et al. COST 327 Motorcycle safety helmets. Luxemboorg, Luxemboorg: European Commission Directorate General for Energy and Transport; 2001. 327p.

10. Brijs K, Brijs T, Sann S, Trinh TA, Wets G, Ruiter RAC. Psychological determinants of motorcycle helmet use among young adults in Cambodia. Transp Res Part F Traffic Psychol Behav 2014; 26:273-90.

11. Papadakaki M, Tzamalouka G, Orsi C, Kritikos A, Morandi A, Gnardellis C, et al. Barriers and facilitators of helmet use in a Greek sample of motorcycle riders: Which evidence? Transp Res Part F Traffic Psychol Behav 2013; 18:189-98.

12. Li LP, Li GL, Cai QE, Zhang AL, Lo SK. Improper motorcycle helmet use in provincial areas of a developing country. Accid Anal Prev 2008; 40(6):1937-42.

13. Zargar M, Khaji A, Karbakhsh M. Pattern of motorcycle-related injuries in Tehran, 1999 to 2000: a study in 6 hospitals. East Mediterr Health J 2006; 12(1-2):81-7.

14. Dua A, Wei S, Safarik J, Furlough C, Desai SS. National mandatory motorcycle helmet laws may save \$2.2 billion annually: An inpatient and value of statistical life analysis. J Trauma Acute Care Surg 2015; 78(6):1182-6.

15. Hyder AA, Waters $H$, Phillips $T$, Rehwinkel J. Exploring the economics of motorcycle helmet laws-implications for low and middle-income countries. Asia Pac J public Health 2007; 19(2):16-22.

16. Croce MA, Zarzaur BL, Magnotti LJ, Fabian TC. Impact of motorcycle helmets and state laws on society's burden: a national study. Ann Surg 2009; 250(3):390-4.

17. Haqverdi MQ, Seyedabrishami S, Groeger JA. Identifying psychological and socio-economic factors affecting motorcycle helmet use. Accid Anal Prev
2015; 85:102-10

18. Ali M, Saeed MM, Ali MM, Haidar N. Determinants of helmet use behaviour among employed motorcycle riders in Yazd, Iran based on theory of planned behaviour. Injury 2011; 42(9):864-9.

19. Keep E. Internal and external incentives to engage in education and training-a framework for analysing the forces acting on individuals? [Monograph Online, No.12]. University of Oxford, Oxford, United Kingdom : SKOPE; 2009 [cited 2009 June]. Available from: https://ora.ox.ac.uk/objects/uuid:99fadf39-cef4-4a9aa7d1-e455c1f623fd

20. Oudeyer PY, Kaplan F. How can we define intrinsic motivation? Paper presentes at: The 8th International Conference on Epigenetic Robotics: Modeling Cognitive Development in Robotic Systems; 2008; Lund University Cognitive Studies, Lund, Brighton, United Kingdom.

21. Ajzen I. The theory of planned behavior. Orgnizational Behav Hum Decis Process 1991; 50(2):179-211.

22. Ajzen I, Driver BL. Application of the theory of planned behaviour to leisure choice. J Leis Res 1992; 24(3):207-24.

23. Lin MR, Kraus JF. A review of risk factors and patterns of motorcycle injuries. Accid Anal Prev 2009; 41(4):710-22.

24. Preusser DF, Hedlund JH, Ulmer RG. Evaluation of motorcycle helmet law repeal in Arkansas and Texas. Washington, D.C. United States: Department of Transportation, National Highway Traffic Safety Administration; 2000 Sep. 60p.

25. Wang P, Rau PL, Salvendy G. Road safety research in China: review and appraisal. Traffic Inj Prev 2010; 11(4):425-32.

26. Kulanthayan S, Umar RS, Hariza HA, Nasir MT, Harwant S. Compliance of proper safety helmet usage in motorcyclists. Med J Malaysia 2000; 55(1):40-4.

27. Skalkidou A, Petridou E, Papadopoulos FC, Dessypris $\mathrm{N}$, Trichopoulos D. Factors affecting motorcycle helmet use in the population of Greater Athens, Greece. Inj Prev 1999; 5(4):264-7. 